\title{
El manejo del idioma en Ciencias de la Educación en la especialidad de Español
}

\author{
Luisa Emilia Ruiz ${ }^{1}$ \\ Luisa Maribel Rodríguez ${ }^{2}$
}

\section{Resumen}

El artículo titulado "El manejo del idioma en Ciencias de la Educación en la especialidad de Español", contiene los resultados de tesis realizada en estudiantes del primer semestre en la Especialidad de Español en el uso de la expresión oral y escrita, durante el segundo semestre del 2009 y primer semestre del 2010, en la modalidad bimestral, URACCAN, Recinto Nueva Guinea.

Se examinó la facilitación del idioma en la expresión oral y escrita de los educandos, y la importancia que implica su manejo adecuado como profesionales en Ciencias de la Educación; así mismo, las barreras que obstaculizan la correcta utilización del lenguaje y las estrategias adecuadas para superar las debilidades y poder comunicar con eficacia sus vivencias endógenas y exógenas que lo insertan a su contexto laboral, familiar y social.

Se encontraron fortalezas y debilidades en el proceso de la comunicación de los estudiantes de primer ingreso en la Especialidad de Español, estas a su vez, permitieron la construcción de una propuesta metodológica con la intención de vigorizar las habilidades verbales, que contribuyan a elevar la calidad educativa que requiere nuestra sociedad; sin embargo, el desarrollo de estas destrezas dependerán del interés y motivaciones de su entorno.

Palabras clave: estudiantes; expresión oral y expresión escrita; vivencias endógenas y exógenas; habilidades verbales.

\section{Summary}

The article entitled "Language management in Educational Sciences in Spanish Specialty" contains the thesis results carried out with students from Spanish Specialty during the first semester, related to the use of oral and written expression in the second semester of 2009 and the first semester of 2010, in the bi-monthly modality, at URACCAN - Nueva Guinea Campus.

Master en Docencia Universitaria e Investigación. Docente de Español. Correo: leruizog@yahoo.com

2 Master en Docencia Universitaria e Investigación. Docente de Español. Correo: luisamaribel65@yahoo.es 
The language facilitation was examined in the student's oral and written expression, as well as the importance of its proper use as professionals in Educational Sciences; also there was a revision of the barriers that hinder the proper use of language and accurate strategies to overcome the weaknesses and be able to effectively communicate their endogenous and exogenous experiences that is inserted in their working, family and social context.

Strengths and weaknesses were found in the communication process of the first-year students from Spanish specialty, which in turn, allowed the construction of a methodological proposal that intended to invigorate the verbal skills that can contribute to raise the education quality that our society requires. However, the development of these skills depends on the interest and motivations of their environment.

Keywords: Students; oral expression and written expression; endogenous and exogenous experiences; verbal skills.

\section{Introducción}

Este artículo es el resultado de la tesis de Maestría en Docencia Universitaria titulada "La comunicación oral y escrita en estudiantes de Ciencias de la Educación con mención en Español". En el marco de la excelencia académica en que está inmersa la Educación Superior en Nicaragua y por supuesto la URACCAN, en búsqueda de la calidad en la formación profesional de cada uno de los estudiantes en sus carreras, se realizó el proceso de auto evaluación institucional que validó la adecuación curricular para el buen desempeño de los egresados en Ciencias de la Educación con mención en Español, con el fin de fortalecer la pertinencia social, cultural, política y profesional que responda a las necesidades y exigencias de la sociedad (URACCAN 2002-2004).

En la comunicación oral y escrita se conjugan elementos como el ambiente familiar, aspectos socioeducativos, relaciones docentes-discentes, ambientes del aula, vocación, capacitaciones, actualizaciones de los docentes en los aspectos pedagógicos y didácticos, importantes para el logro de la enseñanza significativa de los estudiantes.

Investigar sobre la comunicación oral y escrita es introducirse a la historia de un estudiantado, que vive ansioso de expresar sus vivencias endógenas y exógenas. La dificultad de comunicar estas vivencias en forma adecuada, motiva al estudio para escudriñar las razones por las cuales existen barreras en la transmisión del mensaje oral y escrito.

A pesar de que en nuestro país se ha pretendido impulsar desde el inicio de los años 90 una reforma educativa desde los enfoques del Constructivismo Humanista, el Conductismo-Academicista sigue vivo en las aulas de clase y afecta a todas las áreas del currículum vigente. En la asignatura de Español se continúa utilizando libros 
cargados de información sobre literatura y gramática, en igual situación están los programas de los diferentes niveles educativos, dejando a un lado el fortalecimiento de la lengua oral y escrita en la praxis comunicativa.

Para la realización de este estudio se aplicaron diferentes instrumentos en la recopilación de la información que permitieron medir y realizar un análisis exhaustivo sobre los factores que incurren en la comunicación oral y escrita del estudiantado. Estos instrumentos brindaron la información necesaria para poder desarrollar este estudio e identificar las fortalezas y debilidades en el proceso de comunicación. De esta forma la información obtenida, brindó elementos para diseñar una propuesta educativa que contribuirá al desarrollo de las competencias comunicativas y fortalecerá la calidad educativa que requiere la universidad.

\section{Revisión de literatura}

\section{a. Teorías del aprendizaje}

Las teorías de aprendizaje a lo largo de la historia se han usado para analizar las instrucciones que percibe el ser humano para insertarse a una sociedad que requiere educandos y profesionales dotados de todas las habilidades y capacidades, las teorías citadas en este estudio han aportado significativas ideas al considerar que las habilidades verbales son de vital importancia, entre estas está:

\section{Teoría conductista}

El campo conductista (Pavlov, Watson, Guthrie, Skinner) tiene relación con dos líneas: el aprendizaje por reforzamiento y el asociacionismo. Esta teoría es pertinente porque, cuando el aprendizaje se vuelve significativo, los estudiantes tratan de modificar su comportamiento, así como la transferencia del aprendizaje, la aplicación adecuada de las teorías de aprendizaje, harán posible que los estudiantes adquieran un aprendizaje estimulante, y de esta manera podrán mejorar su expresión oral y escrita.

\section{b. El proceso comunicativo, desde la perspectiva interactiva}

\section{La comunicación oral}

"La comunicación oral, resulta más fácil que la escrita, porque además de los signos sonoros, cuenta con más recursos de expresividad: inflexiones de voz con el énfasis, pausa o silencio, mirada, sonrisa, gestos y movimientos corporales" (Domínguez, 200o). 
EDUCACIÓN

\section{c. La comunicación escrita}

León Mejía, (2008) expresa:

La escritura ha permitido la transmisión del conocimiento de generación en generación, es memoria de la humanidad, ha sido de vital importancia para el desarrollo humano, no obstante, al desarrollo tecnológico en materia de comunicación. A pesar de la importancia relacionada al lenguaje dentro de los planes de estudio, estudiantes y profesionales presentan serias deficiencias en la comunicación escrita, tanto en redacción como en asimilación de la lectura.

\section{d. Barreras en el proceso de la comunicación}

Enciclopedia Zamora (2007), manifiesta que existen otras barreras que interfieren en el proceso de la comunicación oral:

- Barreras semánticas: Radica en la acepción del lenguaje en general.

- Barreras físicas: Selección inadecuada de medio para emitir el mensaje.

- Barreras fisiológicas: Ocasionadas por disfunciones y otras limitaciones de personas que intervienen en el proceso comunicativo.

- Barreras Psicológicas: Manera personal para percibir y comprender el mundo, prejuicios y necesidad de satisfacer requerimientos emotivos.

\section{Materiales y métodos}

Los instrumentos aplicados fueron: entrevistas a las autoridades de URACCAN, grupo focal (10 estudiantes) y observación directa a 27 estudiantes. Estos instrumentos proporcionaron la información para poder identificar las fortalezas y debilidades en el proceso de comunicación. De este modo la información obtenida, brindó elementos para diseñar una propuesta metodológica con la intención de ser aplicada en los cursos propedéuticos que coadyuve al desarrollo de las competencias comunicativas, y fortalecer las habilidades verbales de los estudiantes de primer ingreso en el recinto universitario.

Este estudio se condujo bajo el modelo descriptivo, lo cual permitió ponderar la información que influía en este fenómeno, así como verificar y describir cuáles eran los agentes que entorpecían el desarrollo de la comunicación oral y escrita en los estudiantes de primer ingreso bimestral con mención en Español. La dimensión de este estudio fue de corte transversal, porque se llevó a cabo en el II Semestre 2009 I Semestre 2010. 


\section{Resultados y discusión}

\section{Factores culturales que intervienen en la comunicación}

Con este estudio se pretendió determinar cuáles son las causas culturales que inciden en el proceso de la comunicación oral y escrita.

Las deficiencias del habla oral y escrita que obstaculizan las actividades de los estudiantes en los diferentes entornos donde deben desempeñarse, se deben al dominio de complementos básicos que estarán en correspondencia con las habilidades verbales en los comentarios de la carrera Licenciatura en Ciencias de la Educación con mención en Español, modalidad bimestral.

Algunos estudiantes que participaron en el grupo focal manifestaron que dentro de las debilidades más sentidas están la timidez y temor de hablar en público, el nerviosismo, sudoración y temblor de las manos, palpitaciones aceleradas del corazón, temblor de la voz, palidez o rubor excesivo, dificultad para respirar, tensión muscular y desvanecimiento; estos síntomas se dan por falta de lectura y dominio de reglas gramaticales, desmotivación desde el hogar hasta la institución educativa, no han logrado ampliar el interés y estimulación idóneas para crear el hábito de lectura comprensiva y adquisición de un léxico apropiado a las necesidades de su contexto socio-educativo, así como el poco contacto con personas con un amplio dominio del idioma. Uno de los diez estudiantes que participó en el grupo focal, expresa: "La práctica de la lectura me ha permitido una gran modificación en mi vocabulario y en mi escritura" (Grupo focal, 19 de junio de 2010). Esto quiere decir que una de las herramientas principales para la adquisición de las habilidades verbales, es la práctica consciente de la lectura.

No se toman en cuenta las correcciones de forma objetiva con la intención de mejorar la redacción de los escritos. Los métodos empleados en la educación primaria y secundaria no son los idóneos y también los que realizaron en la modalidad a distancia, y prevalece la desmotivación.

La timidez y el temor al hablar, como se alude en el marco teórico en el acápite: obstáculos y dificultades en la comunicación oral, según Müller (2004); así mismo, son impedimentos que dificultan la comunicación oral, ya que provocan tensiones emocionales que llegan a bloquear las facultades mentales y a producir dificultad en la emisión de voz, incoherencia en la expresión de sus ideas y hasta el descontrol de los movimientos corporales. Además, otro factor cultural importante es la resistencia a la corrección, aunque el emisor conozca las expresiones verbales idóneas para la comunicación, está en primer lugar su idiosincrasia y es lo que prevalece a pesar de los continuos llamados al uso claro, preciso y coherente del idioma. 


\section{Factores culturales que intervienen en la comunicación escrita}

Escribir bien es una técnica, y como tal puede aprenderse. Es cuestión de método, interés, trabajo y ejercicio. La buena escritura no nace con el hombre, se hace y se construye mediante nuestras necesidades e intereses; y luego, se convierte en nuestro estilo personal, por lo tanto, los problemas que están afectando la comunicación escrita son: el poco dominio de reglas gramaticales y ortográficas, la poca práctica de redacción, el poco hábito de lectura, el poco dominio para interpretar, analizar y redactar las ideas con lógica, así como las limitaciones de la escucha y el habla; todas estas desventajas de la comunicación escrita no han permitido la transmisión del conocimiento de manera horizontal.

\section{Agentes exógenos que incurren en la expresión oral y escrita}

Las variaciones que sufre la lengua a través del tiempo no ocurren uniformemente en todas las zonas donde se habla: los cambios pueden producirse en un lugar solamente, o pueden evolucionar de distinta manera en las diversas zonas en que se hable la lengua oral y escrita, de acuerdo con los factores históricos, políticos, sociales, económicos y culturales. Estos factores son los que determinan el mayor o menor grado de intercomunicación entre los diversos núcleos del hablante de una comunidad, lo que suscita diferencias dialectales en la expresión oral y escrita.

Las autoridades percibieron que entre los agentes exógenos sobresalen:

Enfrentarse a una nueva modalidad exigente cuando los estudiantes no traen una buena base académica, poco acceso a la información y tecnología, además carecen de una cultura de auto preparación. La televisión e internet influyen en que se hable con muchos modismos, escriban con mala ortografía y se tenga poco hábito de lectura.

\section{Los principales agentes exógenos}

Según los informantes de los grupos focales consideran que entre los agentes exógenos que incurren en la expresión oral y escrita están:

Limitaciones económicas para la compra de bibliografía, material de apoyo en las diferentes asignaturas. No se toman en cuenta las correcciones de forma objetiva con la intención de mejorar la redacción del escrito. La pedagogía educativa recibida en la educación primaria y secundaria no fue la más idónea, sobre todo los egresados de la modalidad a distancia (Grupo focal, 19 junio 2010).

En el entorno familiar, sólo se habla lenguaje coloquial, de tal manera que los estudiantes escriben como hablan y la mayoría proviene de la zona rural donde existen ciertas limitaciones que dificultan la actualización de los conocimientos. 


\section{Agentes endógenos que incurren en la comunicación oral y escrita}

Los agentes endógenos que se manifiestan: el descuido propio y la falta de voluntad, no hay capacidad para asimilar muchas palabras y a la vez con fluidez, no hubo seguimiento desde la educación inicial hasta la actualidad para el mejoramiento de estas habilidades.

Prevalece la idiosincrasia a pesar del conocimiento correcto al momento de exponer sus ideas en público, el vocabulario es pobre, uso excesivo de muletillas, vicios lingüísticos, fenómenos fonéticos de supresión o de incrementación, dicción imprecisa, excesiva gesticulación, entonación incorrecta, ideas incoherentes; y desorganizadas y ausencia de estrategias para organizar el discurso.

Todo hablante de una lengua (oral y escrita) debe aspirar a conocer y manejar eficientemente el sistema general de la lengua, de la misma manera saber usar apropiadamente las variantes dialectales propias de su zona o región.

El componente de expresión oral y escrita es un elemento importante que permite el desarrollo de habilidades verbales. Por esta razón se realizó propuesta metodológica para ser aplicada en los Cursos Propedéuticos enfocados en el desarrollo de destrezas verbales para ingresar a cualquier carrera universitaria.

En todos los niveles de enseñanza deben incorporarse los componentes básicos de la comunicación humana, tratándolos con el análisis y la profundidad que el proceso de maduración del estudiantado permita.

\section{Conclusiones}

La comunicación oral y escrita es de vital importancia para todas las actividades en las que nos desenvolvemos, ya que es la expresión del pensamiento y se considera al hombre y la mujer como seres de palabras, capaces de transmitir todo lo que sienten.

\section{Factores culturales que intervienen en la comunicación oral y escrita}

Algunos factores culturales provocan alteraciones y tensiones en el sistema nervioso, bloqueando las actividades mentales, ocasionando dificultad en la emisión de voz, incoherencia en la expresión de ideas y descontrol en sus movimientos corporales. Otro agente es el apego a su idioma, la resistencia al empleo correcto del idioma acorde a las reglas establecidas no lo llevan a la práctica, frenando así la fluidez del lenguaje oral. 
Mínimo interés por el dominio de las reglas gramaticales y ortográficas, poca práctica de la redacción, así como la insuficiente lectura, todos estas deficiencias crean desventajas que limitan la expresión lógica del habla y la escritura, ya que para lograr una comunicación eficaz, es preciso el manejo y uso pertinente de las habilidades verbales.

\section{Agentes endógenos y exógenos que incurren en el desarrollo de la expresión oral y escrita}

Los factores internos y externos que determinaron el desarrollo de la expresión oral y escrita son los siguientes: Las limitaciones económicas, la falta de material bibliográfico, así como padecimientos psicosomáticos y la falta de tiempo para el desarrollo de esta competencia, además del mal empleo de métodos de enseñanza en las modalidades educativas anteriores, falta de autopreparación, poco acceso a la tecnología y otros medios de comunicación, desmotivación en el desempeño de las habilidades básicas del lenguaje, por tanto, esto ocasiona la separación de los requerimientos que todo estudiante en Ciencias de la Educación con mención en Español se obliga a dominar, porque es preciso estar acorde a las exigencias y transformaciones actuales de la sociedad.

\section{Lista de referencias}

Domínguez, F. Marroquín, A. \& Velasco, M. F. (2000). Técnicas de expresión oral y escrita. $1^{a}$ edición, San Salvadora, El Salvador, UCA Editores.

León Mejía, A. B. (2008). Estrategias para el desarrollo de la comunicación profesional. $2^{\mathrm{a}}$ edición, México, Limusa, $252 \mathrm{pp}$.

Müller Delgado, M. V. (2004). Técnicas de comunicación oral. $1^{\mathrm{a}}$ edición, $3^{\mathrm{a}}$ reimpresión, San José, C. R.: Editorial de la Universidad de Costa Rica.

Pavlov, Iván Petróvich (1927). Teoría conductuales del aprendizaje. Disponible en línea (consultado el 3/o1/2016: http://galeon.com/nada/parte2.pdf 